\title{
Efeitos de dicas visuais na aprendizagem do nado crawl para alunos surdos
}

\author{
Silmara C. Pasetto 1 \\ Paulo F. de Araújo 2 \\ U mberto C. Corrêa 3
}

https://doi.org/10.5628/rpcd.06.03.281

\author{
${ }^{1}$ Centro U niversitário H ermínio 0 metto - UNIARA RAS \\ A raras \\ Brazil \\ 2 Universidade Estadual de Campinas - FEF \\ Campinas \\ Brazil \\ 3 Universidade de São Paulo - LACOM \\ São Paulo \\ Brazil
}

\section{RESUMO}

O objetivo desta pesquisa foi de investigar os efeitos da utilização de diferentes dicas visuais na aprendizagem do nado crawl para alunos surdos. Participaram do estudo 22 alunos, de ambos os sexos, com idades entre 10 e 17 anos. A pesquisa envolveu dois grupos ( $\mathrm{Gl}$ =dicas através de modelo e $\mathrm{G} 2=$ dicas através de figuras e modelo) e três fases experimentais (préteste, aprendizagem e pós-teste). Tanto no préteste quanto no pós-teste os grupos foram filmados e avaliados por um "instrumento de avaliação do nado crawl". Utilizou-se como medida de aprendizagem o padrão do nado crawl, a distância nadada e a quantidade de paradas. Porém obteve-se resultados significantes apenas no padrão do nado crawl. Dessa forma, os resultados da análise intra-grupo mostraram que em ambos os grupos houve melhora do pré para o pós-teste em termos do padrão de movimento. Os resultados da análise inter-grupos mostraram superioridade do grupo $\mathrm{G} 2$ em relação ao G1 no padrão de movimento (componentes 2 e 3), no pós-teste. Pôde-se concluir que a utilização de dicas nas figuras ilustrativas associadas às dicas no modelo real e simulado adicionou informação que permitiu o direcionamento e a manutenção da atenção dos aprendizes aos pontos chaves da habilidade.

Palavras-chave: dicas visuais, aprendizagem motora, surdez, atenção seletiva.

\section{ABSTRACT \\ Visual cues effects in the swim crawl learning to deaf students}

The goal of this study was to investigate the effect of different visual cues in the swim crawl learning to deaf students. Twenty-two students of both sex, between 10 and 17 years of age participate of the study. The research involved two experimental groups $(G 1=$ cues through model and G2 = cues through figure and model) and three phases (pretest, learning, and post-test). In both tests the groups were filmed and evaluated by the "swim crawl evaluation instrument". Were utilized measure of learning the movement pattern, the distance performed and the quantity of the stopped. H owever, significant results were obtained in the intra-group analysis. The results of the intra-group analyses showed that both groups bettered the movement pattern from pre to post-test. The results of the inter-group analyses shown superiority of the group $\mathrm{G} 2$ in comparing with the group $\mathrm{G} 1$ in terms of the components two and three of the movement pattern. Could conclude that the cues in both aspects (figure and model) permitted additional information in relation to cues only in the model. Furthermore, it does that the student direct and maintains her/his attention to the key points of the skill.

Key-Words: visual cues, motor learning, deaf, selective attention. 


\section{INTRODUÇÃO}

O que existe de mais típico na ação do profissional de Educação Física? A instrução, ou seja, o ato de orientar, direcionar e instruir o aluno por meio de verbalização e/ ou demonstração. Existem muitos fatores que interferem no processo de instrução como, por exemplo, o excesso de informações que podem ser prejudiciais ou a falta de informações que podem não ser suficientes para dirigir atenção do aluno à informação relevante na realização de tarefas motoras. E como se sabe, a eficiência na realização de uma atividade motora está muito relacionada à capacidade de utilizar as informações relevantes, para que estas sejam processadas e transformadas em ações (12, 24).

$\mathrm{O}$ ato de separar as informações relevantes das informações irrelevantes do meio ambiente e/ ou tarefa é denominado de processo de atenção sel etiva, sendo que a utilização de dicas é um fator essencial nesse processo $(2,12,13)$. Uma dica se caracteriza por frases concisas, muitas vezes uma ou duas palavras, que ou direcionam a atenção do aprendiz a um aspecto rel evante da tarefa, ou ressal tam el ementos chaves do padrão de movimento. Elas têm sido, muitas vezes, utilizadas como um método alternativo para transmitir informações sobre a tarefa $(2,5,14,16,18,20)$.

Em sua mai oria, estudos sobre a utilização de dicas têm demonstrado efeitos positivos em diversas situações de aprendizagem $(2,3,11,14,15,16,20,28)$. Porém, um aspecto importante a se destacar é que os efeitos de dicas na aprendizagem de habilidade motoras é dependente de como elas são utilizadas (13).

As dicas têm sido utilizadas relativas ao padrão de movimento como um todo (por exemplo "desenhar um coração" caracterizando a braçada do nado peito na natação) ${ }^{(22,24)}$ e a componentes específicos do padrão de movimento (por exemplo, a frase "ponha a mão na cesta", cuja intenção seria transmitir ao arremessador de basquetebol, uma imagem da posição da sua mão depois que ele arremessa a bola). Verificase, também, a utilização de dicas referentes a parâmetros do movimento como, por exemplo, "bater a perna mais rápida ou mais devagar" para correção da pernada do nado crawl (24). Independentemente da ênfase na dica, tem sido sugerido que as mesmas sejam dadas em relação a uma seqüência de prioridades/necessidades de aprendizagem (16).
No entanto, um outro aspecto importante a se destacar é que a eficiência de dicas na aprendizagem é dependente de outros aspectos como o tipo de tarefa ( aberta, fechada, etc.) e a população de aprendizes (idosos, atletas, deficientes, etc). Esse último aspecto implica, também, no tipo de dica, isto é, dicas auditivas (verbais, sonoras, com tons de voz, etc), visuais (cor, forma, figura, modelo, etc), cinestésicas (toque, linguagem corporal, etc) e/ ou auto-dicas (própria orientação) $(4,5,16,24)$.

Os efeitos de dicas na aprendizagem de habilidades motoras têm sido foco de intensas investigações no campo da A prendizagem Motora nas últimas décadas $(16,24)$. Contudo, em sua maioria, essas investigações têm se referido a dicas verbais e à aprendizagem em ambientes de laboratório. Considerando que há aprendizes aos quais a dica verbal poderia não ter eficiência como, por exemplo, aqueles com deficiência auditiva/ surdos, o presente trabal ho teve como objetivo investigar os efeitos da utilização de diferentes dicas visuais na aprendizagem de habilidades motoras por parte desses indivíduos (surdos). As considerações acima implicaram, aliadas ao fato de que poucas pesquisas têm sido relacionadas à aprendizagem de indivíduos com "necessidades especiais", na realização do estudo em situação real de ensinoaprendizagem, isto é, em ambiente e com tarefa com al to grau de validade ecológica.

\section{MÉTODO}

Alunos

O presente estudo contou com a participação voluntária de 22 al unos surdos ( surdez neurossensorial de moderada a profunda, unilateral e/ ou bilateral, com comunicação gestual, leitura labial, de forma oral e através de língua de sinais) de ambos os sexos com idade cronológica entre 10 a 17 anos. Os alunos estudavam em duas escolas de educação especial de Campinas, as quais utilizam, respectivamente, o bilingüismo e a comunicação total como modelos educacionais.

\section{Tarefa e Instrumento}

A tarefa de aprendizagem consistiu no nado crawl. A avaliação do padrão do nado crawl (pré e pósteste), foi realizada por meio de um "instrumento de avaliação do nado crawl" (Quadro 1) Esse instru- 
mento possibilita acessar a aprendizagem do nado crawl em diferentes fases de aprendizagem (padrão nado cachorrinho, coordenação inicial, crawl rudimentar, crawl intermediário, crawl avançado, e em diferentes componentes (posição do corpo, posição da cabeça, respiração, ação dos braços, ação das pernas), sendo que para cada componente existem cinco fases de aprendizagem, F1, F2, F3, F4 e F5, que considera desde o não executar (F1) até a últi- ma fase (F5), que é a execução correta do nado crawl. Embora se verifique referências a esse instrumento na literatura em Educação Física e Desporto $(17,27)$, a utilização do mesmo foi precedida por um processo de validação critério/ referenciada ao domínio (26) por três profissionais/ especialista da área. Em outras palavras, procurou-se adequar o referido instrumento à sua proposta de avaliação: a aprendizagem do nado crawl.

Quadro 1: Componentes e fases de aprendizagem do nado crawl.

\begin{tabular}{|c|c|}
\hline $\begin{array}{c}\text { COMPONENTES DO NADO } \\
\text { CRAWL }\end{array}$ & FASES DE APRENDIZAGEM DO NADO CRAWL \\
\hline $\begin{array}{c}\text { POSICÃODO } \\
\text { CORPO }\end{array}$ & $\begin{array}{l}\text { FASE } 1 \text { - Não executa, não tira os pés do chão } 90^{\circ} \text {. } \\
\text { FASE } 2 \text { - Corpo inclinado } \pm 45^{\circ} \text { em relação à água. } \\
\text { FASE } 3 \text { - Corpo ligeiramente inclinado } \pm 30^{\circ} \text {, dependendo muito da ação das pernas. } \\
\text { FASE } 4 \text { - Corpo próximo à horizontal } \pm 15^{\circ} \text { em relação à água. } \\
\text { FASE } 5 \text { - Na horizontal menos que } \pm 10^{\circ} \text { em relação à água. }\end{array}$ \\
\hline $\begin{array}{l}\text { POSIÇÃO DA } \\
\text { CABEÇA }\end{array}$ & $\begin{array}{l}\text { FASE } 1 \text { - Totalmente fora da água. } \\
\text { FASE } 2 \text { - Elevação da cabeça à frente } \\
\text { FASE } 3 \text { - Cabeça muito alta (água na altura da testa), ou muito baixa em relação ao nível da água. } \\
\text { FASE } 4 \text { - Cabeça um pouco alta ou um pouco baixa, mas que não interfere na execução do nado. } \\
\text { FASE } 5 \text { - Água no nivel do "topo" da cabeça. }\end{array}$ \\
\hline RESPIRAÇÃO & $\begin{array}{l}\text { FASE } 1 \text { - Não executa. } \\
\text { FASE } 2 \text { - Controle respiratório [Bloqueio e Expiração) em deslocamento "Tipo padrão - nado } \\
\text { cachorrinho".. } \\
\text { FASE } 3 \text { - Padrão respiratório frontal com sincronização das braçadas. } \\
\text { FASE } 4 \text { - Respiração lateral com elevação da cabeça durante a sincronização das braçadas, } \\
\text { podendo haver diminuição do ritmo das braçadas durante a inspiração, com rolamento do corpo. } \\
\text { FASE } 5 \text { - Sincronização das braçadas com respiração lateral e/ou bilateral executada de forma } \\
\text { ritmica e constante, sem elevação da cabeça e com rolamento apropriado. }\end{array}$ \\
\hline $\begin{array}{l}\text { AÇÃODOS } \\
\text { BRAÇOS }\end{array}$ & $\begin{array}{l}\text { FASE } 1 \text { - Não executa. } \\
\text { FASE } 2 \text { - Movimentos alternados de braços sem que seja feita recuperação fora da água "Tipo } \\
\text { padrão - nado cachorrinho": - na puxada: empurrão descendente pequeno [círculos]. } \\
\text { FASE } 3 \text { - Movimentos de braços alternados: - na recuperacão: braços com os cotovelos estendidos } \\
\text { (reto); - na puxada: braços com puxar-empurrar longo. } \\
\text { FASE } 4 \text { - Movimentos de braços mais longos e sincronizados: - na recuperação: cotovelos } \\
\text { flexionados; - na puxada: tração com mudança de direção. } \\
\text { FASE } 5 \text { - Movimentos de braços mais longos e sincronizados: - na recuperação: braços relaxados, } \\
\text { cotovelo alto e flexionado; - na puxada: padrão retilineo [s] com ênfase na finalização; e na } \\
\text { pegada: mão na direção do ombro. }\end{array}$ \\
\hline $\begin{array}{l}\text { AČ̃̃O DAS } \\
\text { PERNAS }\end{array}$ & $\begin{array}{l}\text { FASE } 1 \text { - Não executa. } \\
\text { FASE } 2 \text { - Movimento de pedalar. } \\
\text { FASE } 3 \text { - Movimento alternado com flexão extensão das pernas na altura dos joelhos. } \\
\text { FASE } 4 \text { - Movimentos alternados a partir da articulação coxo-femural com instabilidade no padrão } \\
\text { de pernadas por ciclo de braçadas. } \\
\text { FASE } 5 \text { - Batimento de pernas alternadas e continuas com padrão regular de pernadas por ciclo de } \\
\text { braçadas. }\end{array}$ \\
\hline
\end{tabular}


Delineamento e procedimento

A pesquisa envolveu dois grupos: dicas através de modelo $(n=12)$ e dicas através de modelo e figura $(n=10)$, respectivamente G1 e G2. Envolveu, também, três fases experimentais (préteste, fase de aprendizagem e pós-teste).

Para a realização dos testes foi determinada uma distância de oito metros $(8 \mathrm{~m})$ como percurso à ser nadado. Essa metragem foi estipulada devido à possibilidade de visual ização adequada do padrão de movimento e para que não ocorresse interferência da fadiga. Dessa forma, tanto no pré-teste quanto no pósteste, todos os indivíduos foram instruídos a realiza- rem o percurso "executando" o nado crawl, o qual era demonstrado através de modelo real e simulado pelo professor que fazia a segurança dentro da água. A filmadora foi posicionada na lateral da piscina, no meio do percurso (4 metros) a ser nadado, de forma a possi bilitar o acompanhamento dos alunos. Assim, os al unos puderam ser filmados diagonalmente de frente, de lado e de diagonal mente de costas (Figura 1). A filmagem possibilitou a análise, através do instrumento de avaliação do nado crawl, das fases em que os alunos se encontravam em relação a todos os componentes do nado.

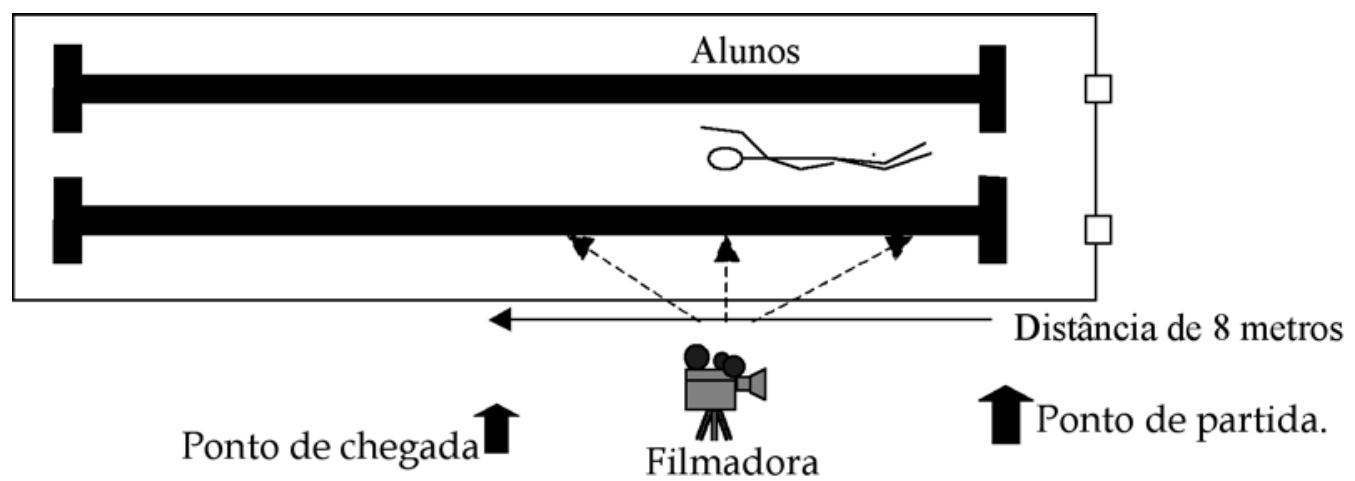

Figura 1: llustração do ambiente de coleta de dados.

Conforme consta anteriormente, para os dois grupos a demonstração teve como base o modelo real e/ ou simulado durante as instruções e como feedback quando necessário. Todas as dicas, bem como o modelo, foram efetuados pelo experimentador. Dessa forma, o grupo G1 recebeu as dicas visuais por meio de modelo real e/ ou simulado e o grupo G2 recebeu as dicas por meio do modelo, igualmente ao G1, e através de figuras ilustrativas do nado crawl. Especificamente, foi destacada uma dica visual e uma dica alternativa (utilizada no caso falta de compreensão e/ ou quando mais adequada em relação ao exercício), relativa a cada componente do nado crawl e a cada fase (Quadro 2). É importante esclarecer que esses procedimentos (dicas e dicas alternativas) são procedimentos comuns utilizados no processo ensino-aprendizagem de habilidades motoras no "mundo real" e encontrados na literatura $(5,6,7,8)$. Para o G2, as dicas através de figuras eram mostradas, um à um, logo após a explicação do exercício, sendo dado como feedback apenas as dicas no modelo. 
Quadro 2: Guia de dicas visuais.

\begin{tabular}{|c|c|c|}
\hline $\begin{array}{c}\text { ASPECTOS MOTORES DO } \\
\text { NADO CRAWL }\end{array}$ & $\begin{array}{c}\text { DICA VISUAL } \\
\text { (MODELO E FIGURA) }\end{array}$ & $\begin{array}{c}\text { DICA VISUAL } \\
\text { ALTERNATIVA } \\
\text { (MODELO E FIGURA) } \\
\end{array}$ \\
\hline $\begin{array}{l}\text { POSICÃO DO CORPO: } \\
\text { Na horizontal menos que }, \pm 10^{\circ} \\
\text { em relação à água. }\end{array}$ & $\begin{array}{l}\text { Fase 1 e 2: Corpo reto. } \\
\text { Fase } 3 \text { e } 4 \text { : Ac elerar o batimento de } \\
\text { pernas. }\end{array}$ & $\begin{array}{l}\text { Fase } 1 \text { e } 2 \text { : Imitar um foguete. } \\
\text { Fase } 3 \text { e } 4 \text { : Nadar rápido. }\end{array}$ \\
\hline $\begin{array}{l}\text { POSIÇÃO DA CABEÇA: } \\
\text { Água no nível do "topo" da } \\
\text { cabeça. }\end{array}$ & $\begin{array}{l}\text { Fase } 1 \text { e } 2 \text { : Olhar para o fundo da } \\
\text { piscina. } \\
\text { Fase } 3 \text { e } 4 \text { : Olhar para frente e para o } \\
\text { fundo ao mesmo tempo. }\end{array}$ & $\begin{array}{l}\text { Fase 1 e 2: Olhar para a barriga. } \\
\text { Fase } 3 \text { e } 4 \text { : Se alta - olhar para a } \\
\text { mão durante a puxada; se baixa - } \\
\text { olhar para a mão durante a } \\
\text { pegada. }\end{array}$ \\
\hline $\begin{array}{l}\text { RESPIRAÇÃO: } \\
\text { Sincronização das braçadas } \\
\text { com respiração lateral e/ou } \\
\text { bilateral executada de forma } \\
\text { ritmica e con stante, sem } \\
\text { elevação da c abeça e com } \\
\text { rolamento apropriado. }\end{array}$ & $\begin{array}{l}\text { Fase } 2 \text { e } 3: \text { Ol ha para frente pega o ar - } \\
\text { cabeça na água faz bolinhas. } \\
\text { Fase 4: Orelha dentro da água. }\end{array}$ & $\begin{array}{l}\text { Fase 1: Olha por c ima da } \\
\text { prancha pega o ar - olha por } \\
\text { baixo da prancha faz bolinhas. } \\
\text { Fase } 2 \text { e 3: Olha para frente pega } \\
\text { o ar - cabeça na água faz som de } \\
\text { "U" } \\
\text { Fase 4: Olhar para a mão na } \\
\text { durante a recuperação. }\end{array}$ \\
\hline $\begin{array}{l}\text { Movimentos de braços } \\
\text { mais longos } \\
\text { sincronizados: } \quad \text { e na } \\
\text { recuperação: raços } \\
\text { relaxados, cotovelo alto e } \\
\text { flexionado; - na puxada: } \\
\text { padrão retilíneo (s) c om } \\
\text { ênfase na finalização; e na } \\
\text { pegada: mão na direção do } \\
\text { ombro. }\end{array}$ & $\begin{array}{l}\text { Recuperação: } \\
\text { Fase 2: Girar o braço fora da água. } \\
\text { Fase 3: I maginar um fio puxando o } \\
\text { cotovelo para cima. } \\
\text { Fase 4: Arrastar as pontas dos dedos n a } \\
\text { água. } \\
\text { Fase da pegada: } \\
\text { Fase 4: Mão na linha do ombro. } \\
\text { Fase puxada: } \\
\text { Fase 1: Cavoucar a água. } \\
\text { Fase 2: Puxar e empurrar a água para } \\
\text { trás. } \\
\text { Fase 3: Encostar o polegar na coxa. } \\
\text { Fase 4: Desenhar um "S" alongado } \\
\text { (invertido para o braço direito) } \\
\text { Fase da finalização: } \\
\text { Fase 4: Jogar água para trás. }\end{array}$ & $\begin{array}{l}\text { Recuperação: } \\
\text { Fase 3: Flexionar o cotovelo. } \\
\text { Fase 4: Encostar o polegar no } \\
\text { ombro. } \\
\text { Fase da pegada: } \\
\text { Fase 4: Cruzar ou abrir à frente. } \\
\text { Fase puxada: } \\
\text { Fase 1: Braçadas em círculos. } \\
\text { Fase 3: Encostar o polegar no } \\
\text { umbigo. } \\
\text { Fase da finalização: } \\
\text { Fase 4: Bater a mão na prancha. }\end{array}$ \\
\hline 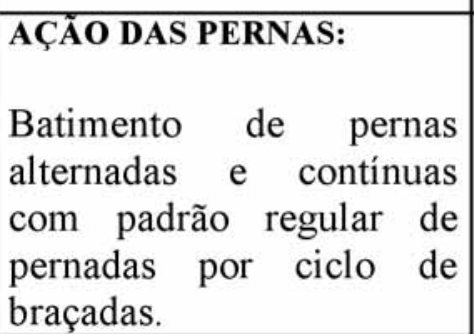 & $\begin{array}{l}\text { Fase 1: Bater o pé na água. } \\
\text { Fase 2: Fazer espuma na água. } \\
\text { Fase 3: Imitar a nadadeira de um } \\
\text { golfinho. } \\
\text { Fase 4: Contar } 6 \text { X1, } 4 \text { X1 e } 3 \text { X1 pernada } \\
\text { por ciclo de braçada }\end{array}$ & $\begin{array}{l}\text { Fase 2: Bater a pé rápido } \\
\text { Fase 3: mergulhar o dedão na } \\
\text { água }\end{array}$ \\
\hline
\end{tabular}


As aulas foram padronizadas de acordo com os componentes do nado crawl e fases de aprendizagem. Foram planejadas duas aulas para cada fase, enfatizando-se sempre o aprendizado do padrão de movimento da fase seguinte, o que totalizou oito aulas. Para cada componente foi elaborado um exercício específico e somente para o componente ação dos braços foi elaborado mais de um exercício devido aos sub-componentes envolvidos. As aulas iniciaram e terminaram da mesma maneira para ambos os grupos G1 e G2, respeitando a individual idade de cada al uno com relação às respectivas fases de aprendizagem. A variável dependente foi a quantidade de indivíduos por grupo em função da distância nadada, da quantidade de vezes que os indivíduos paravam durante a execução e das fases e componentes do padrão de movimento (nado crawl).

\section{RESULTADOS}

Foram feitas comparações intragrupos relacionadas às três medidas, comparando os resultados de cada grupo individualmente do préteste para o pós-teste, sendo que para isso utilizou-se do teste Wilcoxon. E, também, foram realizadas comparações intergrupos, comparando os resultados entre os grupos G1 e G2 no pré e no pós-teste, sendo utilizado para estas comparações o teste $U$ de Mann-Whitney. O padrão do nado crawl foi analisado, tanto no pré teste quanto no pós-teste, com relação à quantidade de al unos em cada fase nos respectivos componentes: C1 (posição do corpo), C2 (posição da cabeça), C3 (respiração), C4 (ação dos braços) e C5 (ação das pernas). Estimou-se a ocorrência de melhora na medida em que houve diminuição da quantidade de alunos nas fases iniciais em detrimento do aumento nas fases mais avançadas (Figura 2). Isso foi confirmado estatisticamente, pois na análise intragrupo do G1 os testes de Wilcoxon encontraram os seguintes resultados: $\mathrm{C} 1(z=2,67 ; p=0,00), C 2(z=2,20 ; p=0,03), C 4$ $(z=2,37 ; p=0,02)$ e $C 5(z=2,02 ; p=0,04)$. Com relação ao C3, devido a baixa variabilidade dos dados não pôde ser realizada a análise inferencial.

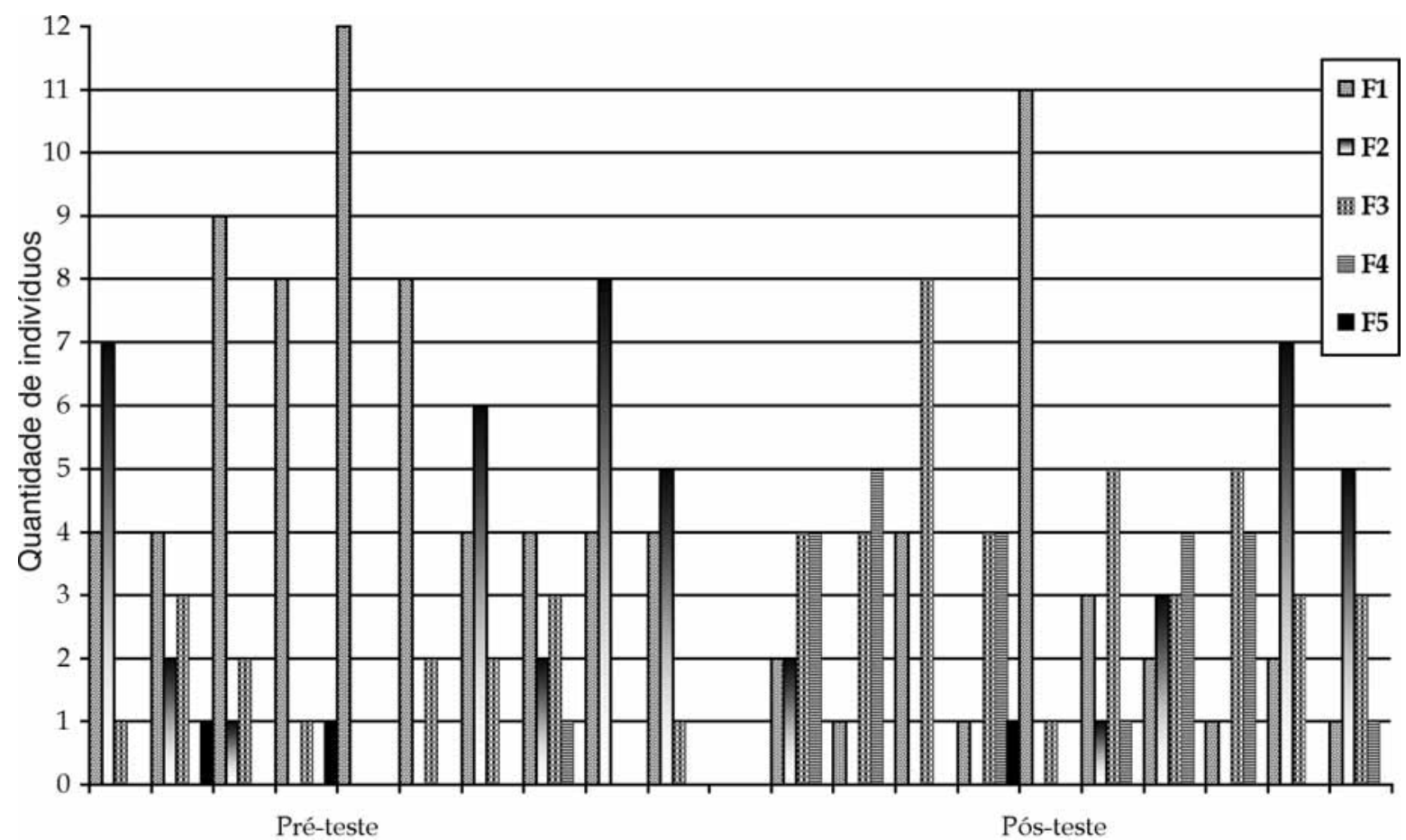

Figura 2: Quantidade de indivíduos dos grupos G1 (M) e G2 (MF) em cada componente (C) do nado crawl, no pré e no pós-teste. 
Com relação ao $\mathrm{G} 2$, os testes de Wilcoxon encontraram os seguintes valores: $\mathrm{C} 1(z=2,31 ; p=0,02), C 2$ $(z=2,52 ; p=0,01), C 3(z=2,20 ; p=0,03), C 4$ $(z=2,37 ; p=0,02)$ e $C 5(z=1,75 ; p=0,08)$. Embora não tenha havido evolução no $C 5$, os resultados permitem afirmar que houve uma evolução do padrão do nado crawl do pré para o pós-teste.

Em síntese, as análises intra-grupos sugerem que em ambos os grupos houve aprendizagem do padrão do nado crawl , com a melhora de quatro componentes. Com respeito às análises inter-grupos, embora se observe diferentes quantidades de indivíduos de cada grupo em ambas as fases experimentais, nos cinco componentes (Figura 2), as mesmas só foram estatisticamente significantes no pós-teste em relação aos componentes C2 e C3. O teste de U MannWhitney encontrou, respectivamente, $z=-2,47 ; p=$ 0,01 e $z=-2,87 ; p=0,00$.

QUADRO 3: Quantidade de alunos nas cinco fases do componente 1 no pré e pós teste do G1 e G2.

\begin{tabular}{|c|c|c|c|c|}
\hline $\begin{array}{l}N^{\circ} \text { de } \\
\text { alunos } \\
\text { PRÉ } \\
\text { TESTE } \\
\text { G1 }\end{array}$ & $\begin{array}{l}\mathrm{N}^{\circ} \mathrm{de} \\
\text { alunos } \\
\text { PRÉ } \\
\text { TESTE } \\
\text { G2 }\end{array}$ & $\begin{array}{l}\text { FASES DE APRENDIZAGEM } \\
\text { DO NADO CRAWL } \\
\text { COMPONENTE 1: } \\
\text { POSIÇÃO DO CORPO }\end{array}$ & $\begin{array}{l}N^{\circ} \text { de } \\
\text { alunos } \\
\text { PÓS } \\
\text { TESTE } \\
\text { G1 } \\
\end{array}$ & $\begin{array}{l}\mathrm{N}^{\circ} \text { de } \\
\text { alunos } \\
\text { PÓS } \\
\text { TESTE } \\
\text { G2 }\end{array}$ \\
\hline 4 & 4 & $\begin{array}{l}\text { F } 1 \text { - Não executa, não tira } \\
\text { os pés do chão } 90^{\circ} \text {. }\end{array}$ & 2 & 1 \\
\hline$?$ & 2 & $\begin{array}{l}\text { F } 2 \text { - Corpo inclinado } \pm 45^{\circ} \\
\text { em relação à água. }\end{array}$ & 2 & 0 \\
\hline 1 & 3 & $\begin{array}{l}\text { F } 3 \text { - Corpo ligeiramente } \\
\text { inclinado } \pm 30^{\circ} \text {, } \\
\text { dependendo muito da ação } \\
\text { das pernas. }\end{array}$ & 4 & 4 \\
\hline 0 & 0 & $\begin{array}{l}\text { F } 4 \text { - Corpo próximo à } \\
\text { horizontal } \pm 15^{\circ} \mathrm{em} \\
\text { relação à água. }\end{array}$ & 4 & 5 \\
\hline 0 & 1 & $\begin{array}{l}\text { F } 5 \cdot \text { Na horizontal menos } \\
\text { que } \pm 10^{\circ} \text { em relação à } \\
\text { água. }\end{array}$ & 0 & 0 \\
\hline
\end{tabular}

QUADRO 4: Quantidade de alunos na cinco fases do componente 2 no pré e pós teste do $\mathrm{Gl}$ e G2.

\begin{tabular}{|c|c|c|c|c|}
\hline $\begin{array}{l}\mathrm{N}^{0} \text { de } \\
\text { alunos } \\
\text { PRÉ } \\
\text { TESTE } \\
\text { G1 }\end{array}$ & $\begin{array}{l}N^{\circ} \text { de } \\
\text { alunos } \\
\text { PRÉ } \\
\text { TESTE } \\
\text { G2 }\end{array}$ & $\begin{array}{l}\text { FASES DE APRENDIZAGEM } \\
\text { DO NADO CRAWL } \\
\text { COMPONENTE 2: } \\
\text { POSIÇÃO DA CABECCA }\end{array}$ & $\begin{array}{l}N^{0} \text { de } \\
\text { alunos } \\
\text { PÓS } \\
\text { TESTE } \\
\text { G1 }\end{array}$ & $\begin{array}{l}\mathrm{N}^{\circ} \text { de } \\
\text { alunos } \\
\text { PÓS } \\
\text { TESTE } \\
\text { G2 }\end{array}$ \\
\hline 9 & 8 & $\begin{array}{l}\text { F } 1 \text {-Totalmente fora da } \\
\text { água. }\end{array}$ & 4 & 1 \\
\hline 1 & 0 & $\begin{array}{l}\mathrm{F} 2 \text { - Elevação da cabeça à } \\
\text { frente }\end{array}$ & 0 & 0 \\
\hline 2 & 1 & $\begin{array}{l}\text { F } 3 \text { - Cabeça muito alta } \\
\text { [água na altura da testa), ou } \\
\text { muito baixa em relação ao } \\
\text { nivel da água. }\end{array}$ & 8 & 4 \\
\hline 0 & 0 & $\begin{array}{l}\text { F } 4 \text { - Cabeça um pouco alta } \\
\text { ou um pouco baixa, mas que } \\
\text { não interfere na execução } \\
\text { do nado. }\end{array}$ & 0 & 4 \\
\hline 0 & 1 & $\begin{array}{l}\text { F } 5 \text { - Água no nivel do "topo" } \\
\text { da cabeça. }\end{array}$ & 0 & 1 \\
\hline
\end{tabular}

QUADRO 5: Quantidade de alunos nas cinco fases do componente 3 no pré e pós teste do G1 e G2.

\begin{tabular}{|c|c|c|c|c|}
\hline $\begin{array}{l}\mathrm{N}^{\circ} \text { de } \\
\text { alunos } \\
\text { PRÉ } \\
\text { TESTE } \\
\text { G1 }\end{array}$ & $\begin{array}{l}N^{0} \text { de } \\
\text { alunos } \\
\text { PRÉ } \\
\text { TESTE } \\
\text { G2 } \\
\end{array}$ & $\begin{array}{l}\text { FASES DE APRENDIZAGEM } \\
\text { DO NADO CRAWL } \\
\text { COMPONENTE 3: } \\
\text { RESPIRACCÃO }\end{array}$ & $\begin{array}{l}\mathrm{N}^{\circ} \text { de } \\
\text { alunos } \\
\text { PÓS } \\
\text { TESTE } \\
\text { G1 } \\
\end{array}$ & $\begin{array}{l}N^{0} \text { de } \\
\text { alunos } \\
\text { PÓS } \\
\text { TESTE } \\
\text { G2 } \\
\end{array}$ \\
\hline 12 & 8 & F 1 - Não executa. & 11 & 3 \\
\hline 0 & 0 & $\begin{array}{l}\text { F 2-Controle respiratório } \\
\text { (Bloqueio e Expiração) em } \\
\text { deslocamento "Tipo padrão } \\
\text {-nado cachorrinho".. }\end{array}$ & 0 & 1 \\
\hline 0 & 2 & $\begin{array}{l}\text { F } 3 \text { - Padrão respiratório } \\
\text { frontal com sincronização } \\
\text { das braçadas. }\end{array}$ & 1 & 5 \\
\hline 0 & 0 & $\begin{array}{l}\text { F } 4 \text { - Respiração lateral } \\
\text { com elevação da cabeça } \\
\text { durante a sincronização } \\
\text { das braçadas, podendo } \\
\text { haver diminuição do ritmo } \\
\text { das braçadas durante a } \\
\text { inspiração, com rolamento } \\
\text { do corpo. }\end{array}$ & 0 & 1 \\
\hline 0 & 0 & $\begin{array}{l}\text { F } 5 \text { - Sincronização das } \\
\text { braçadas com respiração } \\
\text { lateral e/ou bilateral } \\
\text { executada de forma ritmica } \\
\text { e constante, sem elevação } \\
\text { da cabeça e com rolamento } \\
\text { apropriado. }\end{array}$ & 0 & 0 \\
\hline
\end{tabular}


Quadro 6: Quantidade de alunos nas cinco fases do componente 4 no pré e pós teste do Gl e G2.

\begin{tabular}{|c|c|c|c|c|}
\hline $\begin{array}{l}N^{\circ} \text { de } \\
\text { alunos } \\
\text { PRÉ } \\
\text { TESTE } \\
\text { G1 }\end{array}$ & $\begin{array}{l}\mathrm{N}^{0} \mathrm{de} \\
\text { alunos } \\
\text { PRÉ } \\
\text { TESTE } \\
\text { G2 }\end{array}$ & $\begin{array}{l}\text { FASES DE APRENDIZAGEM } \\
\text { DO NADO CRAWL } \\
\text { COMPONENTE 4: AÇÃO } \\
\text { DOS BRAÇOS }\end{array}$ & $\begin{array}{l}N^{\circ} \text { de } \\
\text { alunos } \\
\text { PÓS } \\
\text { TESTE } \\
\text { G1 } \\
\end{array}$ & $\begin{array}{l}\mathrm{N}^{\circ} \mathrm{de} \\
\text { alunos } \\
\text { PÓS } \\
\text { TESTE } \\
\text { G2 }\end{array}$ \\
\hline 4 & 4 & F 1 - Não executa. & 2 & 1 \\
\hline 6 & 2 & $\begin{array}{l}\text { F } 2 \text { - Movimentos } \\
\text { alternados de braços sem } \\
\text { que seja feita recuperação } \\
\text { fora da água "Tipo padrão - } \\
\text { nado cachorrinho": - na } \\
\text { puxada: empurrão } \\
\text { descendente pequeno } \\
\text { (círculos). }\end{array}$ & 3 & 0 \\
\hline 2 & 3 & $\begin{array}{l}\text { F } 3 \text { - Movimentos de braços } \\
\text { alternados:- na } \\
\text { recuperação: braços com os } \\
\text { cotovelos estendidos } \\
\text { (reto); - na puxada: braços } \\
\text { com puxar-empurrar longo. }\end{array}$ & 3 & 5 \\
\hline 0 & 1 & $\begin{array}{l}\text { F } 4 \text { - Movimentos de } \\
\text { braços mais longos e } \\
\text { sincronizados: - na } \\
\text { recuperação: cotovelos } \\
\text { flexionados; - na puxada: } \\
\text { tração com mudança de } \\
\text { direção. }\end{array}$ & 4 & 4 \\
\hline 0 & 0 & $\begin{array}{l}\text { F } 5 \text { - } \\
\text { Movimentos De Braços Mais } \\
\text { Longos E Sincronizados: - } \\
\text { Na Recuperação: Braços } \\
\text { Relaxados, Cotovelo Alto E } \\
\text { Flexionado; - Na Puxada: } \\
\text { Padrão Retilíneo (S) Com } \\
\text { Ênfase Na Finalização; E Na } \\
\text { Pegada: Mão Na Direção Do } \\
\text { Ombro. }\end{array}$ & 0 & 0 \\
\hline
\end{tabular}

QUADRO 7: Quantidade de alunos nas cinco fases do componente 5 no pré e pós teste do G1 e G2.

\begin{tabular}{|c|c|c|c|c|}
\hline $\begin{array}{l}\mathrm{N}^{0} \text { de } \\
\text { alunos } \\
\text { PRÉ } \\
\text { TESTE } \\
\text { G1 }\end{array}$ & $\begin{array}{l}\mathrm{N}^{0} \text { de } \\
\text { alunos } \\
\text { PRÉ } \\
\text { TESTE } \\
\text { G2 }\end{array}$ & $\begin{array}{l}\text { FASES DE APRENDIZAGEM } \\
\text { DO NADO CRAWL } \\
\text { COMPONENTE 5: AÇÃO } \\
\text { DAS PERNAS }\end{array}$ & $\begin{array}{l}\mathrm{N}^{\circ} \text { de } \\
\text { alunos } \\
\text { PÓS } \\
\text { TESTE } \\
\text { G1 }\end{array}$ & $\begin{array}{l}N^{0} \text { de } \\
\text { alunos } \\
\text { PÓS } \\
\text { TESTE } \\
\text { G2 }\end{array}$ \\
\hline 4 & 4 & F 1 - Não executa. & 2 & 1 \\
\hline 8 & 5 & $\begin{array}{l}\text { F } 2 \text { - Movimento de } \\
\text { pedalar. }\end{array}$ & $?$ & 5 \\
\hline 0 & 1 & $\begin{array}{l}\text { F } 3 \text { - Movimento alternado } \\
\text { com flexão extensão das } \\
\text { pernas na altura dos } \\
\text { joelhos. }\end{array}$ & 3 & 3 \\
\hline 0 & 0 & $\begin{array}{l}\text { F } 4 \text { - Movimentos } \\
\text { alternados a partir da } \\
\text { articulação coxo-femural } \\
\text { com instabilidade no } \\
\text { padrão de pernadas por } \\
\text { ciclo de braçadas. }\end{array}$ & 0 & 1 \\
\hline 0 & 0 & $\begin{array}{l}\text { F } 5 \text { - Batimento de pernas } \\
\text { alternadas e contínuas } \\
\text { com padrão regular de } \\
\text { pernadas por ciclo de } \\
\text { braçadas. }\end{array}$ & 0 & 0 \\
\hline
\end{tabular}

Considerando que, por natureza, o ato de nadar diz respeito a deslocamento, a distância percorrida foi tomada como uma importante variável dependente (Figura 3). As análises intragrupos mostraram que houve um aumento na quantidade de alunos que realizaram distâncias maiores do pré para o pós-teste em ambos os grupos. Contudo o teste de Wilcoxon só foi possível de ser realizado com os dados do $\mathrm{G} 1$ $(z=2,20 ; p=0,03)$. 


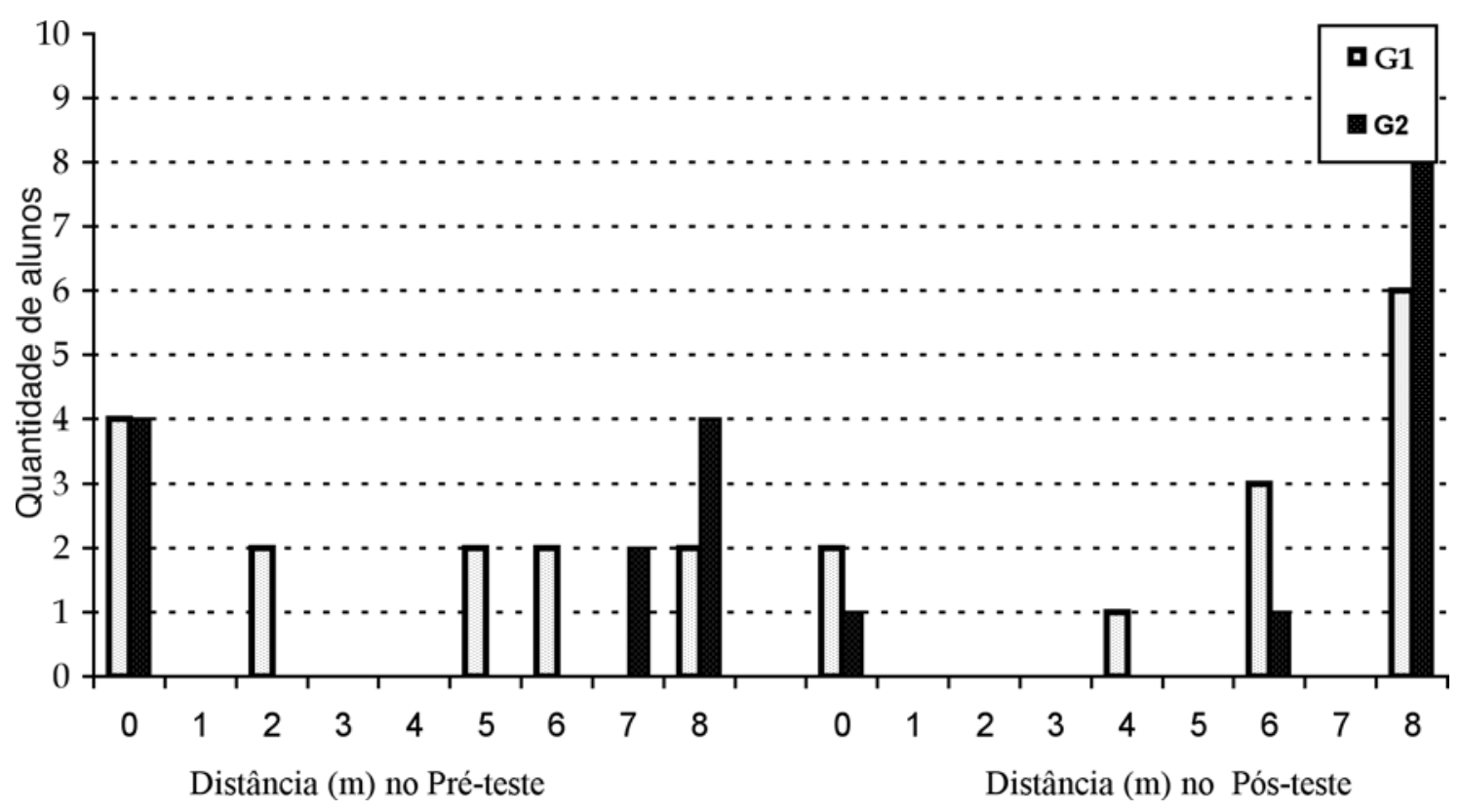

Figura 3: Quantidade de indivíduos e distância nadada no pré e no pós-teste em ambos os grupos experimentais.

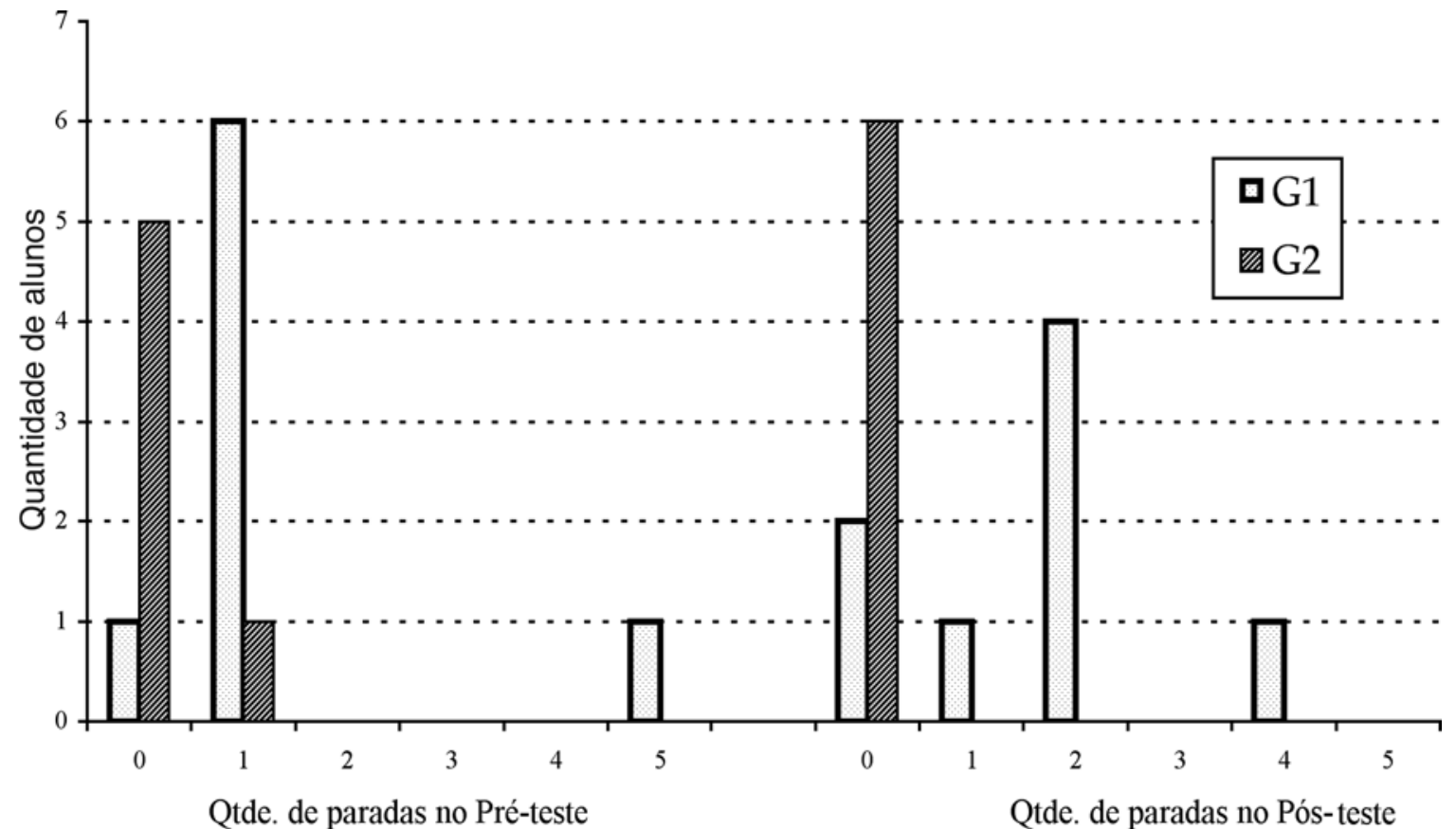

Figura 4: Quantidade de alunos e quantidade de paradas dos grupos G1 e G2 no pré e no pós-teste. 
Em termos da análise inter-grupos, o teste $U$ de Mann-Whitney mostrou que os grupos foram diferentes apenas no préteste $(z=2,16025$; $p=0,030761$ ). Essa análise reforça que houve um aumento na quantidade de alunos do G1 que passaram a nadar distâncias maiores, tornado-se muito parecido com G2, apesar de G2 ainda ter mais alunos nas distâncias maiores.

Finalmente, concernente à quantidade de paradas que os indivíduos efetuaram durante a realização do nado (Figura 4), analisou-se desde a quantidade de alunos que não paravam até a quantidade de alunos que paravam cinco vezes, independente da distância realizada. Percebeu-se que os alunos que paravam mais do que cinco vezes enquadravam-se na categoria "não realizaram a tarefa". Apesar de se observar diferenças entre o pré e o pós-teste em ambos os grupos, isso não foi confirmado pela análise inferencial. O teste de Wilcoxon encontrou $z=1,21 ; p=0,22$ para o G1. A análise inferencial não foi capaz de ser conduzida para o G2.

No que diz respeito à comparação inter-grupos, o teste estatístico mostrou que os grupos foram diferentes em ambas as fases do experimento (pré e pósteste). Observa-se que já no préteste o G2 possuí apenas 1 aluno que parava 1 vez, enquanto em G1 havia uma concentração mai or na quantidade de alunos que paravam 1 vez, além de ter 1 aluno que parava 5 vezes. No pós-teste, os alunos de G2 passaram a nadar sem realizar nenhuma parada, porém no G1 houve um aumento na quantidade de alunos com 2 paradas. Tais dados sugerem que tanto no pré como no pós-teste, o G2 se apresenta com melhores resultados comparado a G1, que além de já no préteste apresentar uma quantidade de paradas maior que G2, no pós-teste aumentou ainda mais essa quantidade. A análise estatística confirma essas diferenças, pois o teste $U$ de Mann-Whitney encontrou no pré-teste $z=2,53 ; p=0,01$ e, no pós-teste, $z=2,94 ; p=0,00$.

\section{DISCUSSÃO E CONCLUSÃO}

Partindo do pressuposto de que, principalmente o surdo com perda auditiva neurossensorial de severa à profunda depende de uma percepção visual aguçada para interagir adequadamente com o meio ambiente, ou seja, para se comunicar e aprender (21).
E, sabendo-se que a utilização de dicas é uma estratégia eficaz no processo de aprendizagem de habilidades motoras, torna-se possível pensar que as dicas visuais poderiam influenciar o processo ensinoaprendizagem de habilidades motoras para al unos surdos.

Considerando que, na comunicação e na interação com o meio, a visão tem para as pessoas surdas à mesma importância que a audição tem para as pessoas ouvintes (10) pode-se presumir que, se a comunicação fosse imprópria, poderia haver conseqüências para o desenvolvimento intelectual, da linguagem, das atitudes emocionais, das relações sociais (23) e também para aprendizagem motora. De acordo com Sacks (23), na falta da audição, a visão e o tato acabam suprindo e organizando al gumas informações, tais como tempo, espaço e outras percepções sensoriais. Porém devido à sobrecarga visual, o surdo possui o que é denominado de atenção dividida (19) ou segmentada, o que lhes permite dar atenção às informações uma de cada vez.

Dessa forma, as dicas, por serem caracterizadas como informações curtas e específicas à tarefa e por serem administradas uma de cada vez, poderiam facilitar o trabal ho com alunos surdos, devido à focalização de sua atenção a elementos chaves da tarefa. Em outras palavras, a compreensão da tarefa poderia ser facilitada. De acordo com Goldfeld (9), a "falta de atenção"do surdo está relacionada à "falta"de compreensão da tarefa e, conseqüentemente, à "falta" de interesse sobre ela.

Outros fatores importantes a serem citados com relação às dicas e os problemas de atenção na surdez refere-se aos benefícios da utilização das dicas visuais. De acordo com Fronske e Collier (6) e Fronske e McGown (8), as dicas visuais auxiliam o al uno na criação de uma imagem mental, melhorando a concentração e, de acordo com Singer (25), a manter a atenção por mais tempo.

Com base no exposto acima, procurou-se investigar os efeitos de dicas visuais na aprendizagem de habilidades motoras para alunos surdos. Especificamente, procurou-se investigar os efeitos de dicas visuais através de modelo e de modelo e de figura na aprendizagem do nado crawl, sendo que se utilizou como medida de aprendizagem, o padrão do nado crawl, a distância nadada e a quantidade de paradas. 
Com relação ao padrão do nado crawl, a partir dos resultados obtidos pôde-se constatar que a utilização de dicas visuais no processo ensino-aprendizagem foi eficaz. Isso porque, ambos os grupos mostraram evolução do pré para o pós-teste em quase todos os componentes. Não houve melhora no C3 (respiração) do G1 e no C5 (ação das pernas) do G2.

Um importante aspecto a se destacar sobre esses resultados diz respeito a não linearidade da citada evolução, ou seja, nem todos os componentes são aprendidos da mesma forma, na mesma vel ocidade ou ao mesmo tempo. Pode-se pensar que isso ocorre porque os componentes se diferenciam em termos de complexidade. Por exemplo, a ação dos braços é mais complexa, ou seja, possui mais elementos do que a posição do corpo. A ação dos braços envolve quatro fases (pegada, puxada, finalização e recuperação, através de flexão, extensão, rotação e circundução). Já a posição do corpo envolve equilíbrio e flutuação. Um outro exemplo refere-se à posição da cabeça, a qual é menos complexa que a respiração. A primeira envolve apenas flexão e extensão do pescoço. Já a respiração envolve, além da flexão e extensão do pescoço, movimentos de rotação, inspiração e à influência de componente sobre o outro. Por exemplo, se o aluno possuir a posição do corpo (C1) muito inclinada, provavelmente executará a pernada com movimentos de pedalar (C5). É o que se observou nos resultados, em que dos 4 al unos do G2 que apresentavam o corpo muito inclinado, mostraram movimentos de pedalar no pós-teste.

Esses resultados dão suporte à proposição de Masser (20) sobre à eficiência de dicas no direcionamento da atenção do aprendiz a pontos chaves da habilidade, além de manter sua concentração durante a prática. De acordo com Singer (25), ambientes de aprendizagem auxiliados visualmente são consi derados extremamente benéficos para o aprendiz, principalmente nos primeiros estágios de aprendizagem. Isso também pode ser verificado em Blischke, Marschall, Muller e Daugs (1) sobre a utilização de modelos e figuras durante à prática.

Já nos resultados intergrupos, verificou-se diferenças significantes entre os grupos no pós-teste, nos componentes C2 (posição da cabeça) e C3 (respiração). Esses resultados mostraram que o grupo G1 que utilizou dicas no modelo e na figura foi mais eficiente quando comparado ao grupo que utilizou apenas de dicas no modelo (G2). Isso porque no pós-teste o grupo com dicas no modelo e na figura apresentou mais indivíduos que colocavam a cabeça dentro d'água e efetuavam a respiração. Uma possível explicação para isso é que esse grupo recebeu dicas sobre o mesmo aspecto de duas formas (modelo e figura) e o outro grupo apenas de uma forma (modelo). 0 que se quer dizer é que pode ter havido uma espécie de reforço no direcionamento da atenção do aprendiz no G2.

De acordo com Blischke, Marschall, Muller e Daugs (1), a utilização de figuras, principalmente aquelas que possuem apenas contornos, possibilita que $o$ aprendiz focalize detal hes do movimento. Além disso, elas são mais atrativas, despertam a curiosidade e o interesse. No caso do modelo, sua visualização possibilita desenvolver uma forte imagem visual da habilidade, além de fornecer informações sobre o que fazer e sobre o erro $(1,16)$.

Conforma citado anteriormente, além da variável padrão do nado crawl, analisou-se também à distância nadada. Os resultados mostraram que o G1 obteve diferença significante do pré para o pós-teste. $O$ que significa que os alunos aumentaram a distância nadada com à prática. No G2 não foi possível realizar a análise estatística devido à baixa variabilidade das distâncias nadadas entre os testes. Nesse grupo, já no préteste os alunos estavam nadando próximo á distância máxima (8m). Com relação a comparação entre os grupos, verificou-se diferenças entre eles apenas no préteste. Esses resultados permitem inferir que o $\mathrm{Gl}$ evoluiu do pré para pós-teste. Na variável número de paradas, os resultados mostraram que não houve diferenças em ambos os grupos do pré para o pós-teste. Ressalte-se que foram considerados somente os alunos que nadaram tanto no pré-teste quanto no pós-teste, assim, os alunos que conseguiram nadar somente no pós-teste não entraram na análise dos dados. Porém, comparando os dois grupos constatou-se que tanto no pré quanto no pós-teste, foram encontradas diferenças significantes. O que significa que os alunos do $\mathrm{G} 2$ paravam menos do que os alunos do G1 no préteste, e isso se repetiu no pós-teste. Em síntese, embora as variáveis "distância e quantidade de paradas" não possibilitem inferências em 
relação ao objetivo da presente pesquisa, a variável padrão do nado crawl permite concluir que os alunos surdos que receberam instruções através de dicas no modelo e na figura, apresentaram uma aprendizagem mais eficaz comparada a aprendizagem realizada com dicas no modelo.

Com relação a futuros estudos, destaca-se que em alguns momentos, durante a realização do experimento, houve a necessidade da experimentadora realizar contato físico com os al unos para auxilia-los na compreensão da tarefa a ser executada. Isso pode remeter a um outro tipo de dica: a cinestésica. Portanto, outras pesquisas poderiam ser realizadas investigando-se os efeitos de dicas visuais associadas e não associadas à dicas cinestésicas, no processo de aprendizagem de habilidades motoras.

\section{CORRESPONDÊNCIA}

\section{Silmara Cristina Pasetto}

Rua Engenheiro Antônio Mayer, 278

Jardim Panorama, Valinhos, São Paulo, Brasil CEP 13277-460

silmap@ uol.com.br 


\section{REFERÊNCIAS}

1. Blischke K, Marschall F, Muller H, Daugs R (1999). Augmented information in motor skill acquisition. In: Auweele YV, Bakker F, Biddle S, Durand M, Seiler R (eds.). Psychology for physical educators. Champaign: Human Kinetics, 257-287

2. Cidade REA (1998). 0 uso de dicas específicas como estratégia de atenção sel etiva em portadores de síndrome de down. Dissertação de Mestrado. FEF-UNICAMP

3. Cidade REA, Tavares MCGFT, Ladewig I (1998a). Aprendizagem motora e cognição em portadores de deficiência. Rev Soc Bras A tiv M ot A dap 3: 17-20

4. Cidade REA, Tavares MCGCF, Ladewig I, Leitão $T$ (1998b). O uso de dicas no tênis de campo com uma criança portadora de Síndrome de Down. Um estudo de caso. Rev Soc Bras A tiv M ot A dap 3: 21-24

5. Fronske HA (2001). Teaching cues for sport skills. $2^{a}$ ed. Utah State University

6. Fronske HA, Collier C (1993). Cueing your athletes in on jumping events. JOPERD 64: 7-9

7. Fronske HA, Collier C (1993). Cueing your participants in on track events. JOPERD 64: 9-10

8. Fronske H, McGown C (1992). Visual teaching cues for volleyball skills. JOPERD 64: 10-11

9. Goldfeld M (1997). A criança surda: linguagem e cognição numa perspectiva sócio-interacionista. São Paulo: Plexus

10. Lacerda CBF, Mantelatto SAC (2000). As diferentes concepções de linguagem na prática fonoaudiológica. In: Lacerda CBF, Nakamura H, Lima MC (orgs.). Fonoaudiologia: surdez e abordagem bilíngüe. São Paulo: Plexus

11. Ladewig I (1994). U se of task specific cues and manipulation of environmental distractors to enhance children's selective attention. Doctoral Thesis. University of Pittsburgh

12. Ladewig I (2000). A importância da atenção na aprendizagem de habilidades motoras. Rev Paul Ed Fís 3: 62-71

13. Ladewig I, Gallagher JD, Campos W (1995). A utilização de dicas específicas como facilitador do aprendizado em crianças. Synopsis 6: 50-53

14. Ladewig I, Campos W, Gallagher ID (1996). Das teorias de atenção às estratégias de atenção seletiva: Uma revisão bibliográfica. Synopsis 7: 81-94

15. Ladewig I, Cidade RE, Ladewig MJ (2001). Dicas de aprendizagem visando aprimorar a atenção seletiva em crianças. In: Teixeira LA (ed.). A vanços em comportamento motor. São Paulo: Movimento, 166-197

16. Landin D (1994). The role of verbal cues in skill learning. Q uest 46: 299-313

17. Langendorfer SJ, Bruya R (1995). A quatic readiness: developing water competence in young children. Champaign: Human Kinetics, 19-84

18. Magill RA (2000). A prendizagem motora: conceitos e aplicações. 5ąed. São Paulo: Edgard Blucher

19. Marchesi A (1995). Comunicação, linguagem e pensamento das crianças surdas. In: Coll C, Palácios J, Marchesi A (Orgs.). D esenvolvimento psicológico e educação: necessidades educativas especiais e aprendizagem escolar vol 3. Porto Alegre: Artes Médicas, 198-214

20. Masser LS (1993). Critical cues help first-grade students' achievement in handstands and forward rolls. J Teach Phys Ed 12: 301-312

21. Northern JL, Downs MP (1989). A udição em crianças. São Paulo: Manole.

22. Rink JE (1993). Teaching physical education for learning. St. Louis: Mosby

23. Sacks OW (1999). Vendo vozes: uma viagem ao mundo dos surdos. São Paulo: Companhia das Letras

24. Schmidt RA, Wrisberg CA (2001). A prendizagem e performance motora. 2a ed. São Paulo: Artmed

25. Singer RN (1980). M otor learning and human performance: an application to motor skills and movement behaviors. 3a ed. New York: MacMillan Publishing Co

26. Thomas JR, Nelson JK (2002). M étodos de pesquisa em atividade física. 3a Ed. Porto Alegre: Artmed

27. Xavier EF (2001). 0 Efeito das restrições da tarefa e do ambiente no comportamento de locomoção no meio aquático. Dissertação de Mestrado. EEFE - USP

28. Ziegler SG (1987). Effects of stimulus cueing on the acquisition of groundstrokes by beginning tennis players. J A pp Behav A nal 20:405-411 